\title{
MUSAS E MÚSICA NOS PLANOS EPISTÊMICOS DA MEMÓRIA NA ANTIGA GRÉCIA
}

\author{
Cynthia Gusmão ${ }^{1}$
}

RESUMO:

O estudo aponta a importância da memória nas indagaçóes epistêmicas da antiga cultura grega. Inicialmente, fala sobre a presença da deusa Mnemosyne e suas filhas Musas no mito hesiódico e em seguida as estratégias mnemônicas para as competiçóes e recitaçóes poéticas. Depois, analisa as mudanças ocorridas com a introdução dos discursos filosóficos nos debates públicos e competiçôes. Em seguida, aborda-se o lugar de Mnemosyne nos cultos órficos e a relaçáo do orfismo pitagórico com o platonismo. Por fim, comenta aspectos do texto aristotélico Sobre a memória e a anamnese observando analogias entre a anamnese aristotélica e a descrição do melos na filosofia musical aristoxeniana.

\section{PALAVRAS-CHAVE:}

música; memória; anamnese; melos; orfismo.

\section{ABSTRACT:}

The study points the bold presence of memory in the episthemic questions of the ancient greek culture. Firts of all, it analyzes the presence of the goddess Mnemosyne and her daughters the Muses in the hesiodic myth and afterwards the mnemonic devices for the poetic competitions and recitations. Then presents the changes that ocurred with the insertion of philosophical discourses in the public debates. Then, it approaches the place of Mnemosyne in the orphic cults and the relationship between the pythagorean orphism and the platonismo. Finally, comments some aspects of the aristotelic text $O n$ memory and recollection observing analogies betwwen the aristotelic anamesis and the melos description in the aristoxenian musical philosophy.

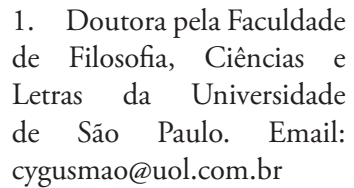

cygusmao@uol.com.br 


\section{KEYWORDS:}

Music; memory; recollection; melos; orphism.

2. A datação dos poemas de Hesíodo é tema de debate entre os estudiosos, mas costuma-se considerar que o poeta tenha vivido no século VII a.C. A respeito disso, ver MAAS \& SNYDER (1989, p. 222, n. 4); e também HAVELOCK (1994, p. 180-2).

\section{A MEMÓRIA ATEMPORAL DO MITO}

No horizonte epistêmico da antiga cultura grega a noção de memória marca sua presença no mito. Na Teogonia de Hesíodo $^{2}$, a genealogia do mundo se inicia com Kaos, seguido de Gea, Tártaro e Eros. De Kaos nascem a Noite e Érebos, e, deles, Éter e Dia, que trazem a luz. Gea pare de si mesma Ouranos (Céu), Ourea (Montanhas) e Póntos (Mar). Em seguida Gea, a Terra, une-se a seu filho Ouranos, para gerar os titãs Oceano, Coios, Crios, Hipérion, Jápeto, Thea, Reia, Têmis, por fim, a deusa da memória Mnemosyne e Cronos. Esses dois últimos titãs instauram a percepção do tempo, seus lapsos e espaços.

Segundo a narrativa hesiódica, Ouranos detestava todos seus filhos titãs e os escondia no interior de Gea, a terra mãe, que gemia. Contudo, a deusa presidia sobre a foice e Cronos, seu filho, toma o artefato agrícola e corta o pênis do pai. Extirpado o poder celeste de Ouranos, Cronos, deus do tempo, assume o poder e recebe o epíteto ankylometis. Metis é o pensamento rápido, certeiro; ankyle, todo objeto curvo ou que se pode curvar, pode ser uma foice, uma corda de um arco ou uma amarra de navio.

Cronos e sua irmá titânide Reia geram os deuses do Olimpo, entre eles, Zeus. Na sucessão genealógica, assim como Cronos havia destronado Ouranos, ajudado por sua mãe, Zeus também o faz com seu pai Cronos, ajudado pela mãe, Reia. Uma das uniôes amorosas de Zeus será com Mnemosyne, dando nascimento às Musas.

Os poetas cantavam esse grande catálogo genealógico do mundo, em uma espécie de metalinguística musical arcaica, em que personagens como Mnemosyne e as Musas indicam a própria razão de existir do ritmo, da dança, do melos do poema, das sonoridades dos sopros, cordas e percussóes. As Musas eram invocadas no prelúdio inicial, no exato momento do esforço inicial da memória, quando o poeta tinha de trazer à tona os elementos de sua composição. 
Homero contou nove Musas, mas náo deu maiores detalhes. Hesíodo faz uma viva descriçáo, que talvez seja a maneira mais próxima de como elas deviam ser cultuadas popularmente. Elas dançam no alto do monte Hélicon, em volta de uma fonte violácea, que é a própria deusa Mnemosyne. O poeta não as vê, pois o alto do monte Hélicon é coberto de névoa. Ele apenas ouve suas vozes e o bater de seus pés na terra. Há um caráter vibratório no movimento dessas musas infatigáveis, que cantam e dançam em torno dessa nascente vital. É uma epifania musical, com dança, canto, ritmo, em volta do fluir ininterrupto da fonte da memória.

A associação da deusa da Memória com nascentes e fontes d'água aparece também no âmbito do orfismo. Em pequenas lâminas de ouro encontradas em túmulos antigos há instruçôes para os mortos de como eles devem suplantar os obstáculos no outro mundo. Elas sublinham a importância de não beberem a água do rio Lethe, o esquecimento, e sim da fonte Mnemosyne, que é associada à sabedoria (cf. BURKERT, 1991, p. 97, n.130).

A recitaçáo de poemas transmitia o arcabouço do saber daquele povo. Em vários momentos, eles sáo verdadeiros catálogos, que, além de proporcionarem um recurso narrativo e mnemônico ao poeta, difundiam o conhecimento da regiáo. Assim, a mitologia grega é uma forma poética, e não um corpo doutrinário, mas é também o receptáculo de um saber. Quando Odisseu narra a construção da sua cama ou diz como testar um arco, esse conhecimento se dissemina. $\mathrm{Na}$ Iliada, por exemplo, temos notícia da geografia da Grécia no catálogo das naus (vv.455-759), na Odisseia, da técnica de construçóes monóxilas, apresentada por Odisseu quando ele conta como construiu sua cama no tronco de uma oliveira (vv. 186-204); no Hino a Hermes, o deus explica em detalhes a construção da lira pela nova técnica de montagem das partes (cf, GUSMÃO, 2015, p. 64-6).

Outro recurso narrativo importante dos poemas épicos, e que é ao mesmo tempo uma técnica mnemônica, é a atribuição de epítetos aos deuses, aos heróis e a alguns objetos; esses epítetos forneciam também apoio aos improvisos. ${ }^{3}$ Por exemplo, o epíteto "de olhos brilhantes" é evocado sempre que aparece a deusa Atena $(\theta \varepsilon \alpha \gamma \lambda \alpha v \kappa \omega \pi ı \varsigma$ A $\theta \eta v \eta)$. Em alguns casos, o epíteto auxilia na elucidação de aspectos de um ob-
3. Nos anos 1930-40, eles foram estudados por Milman Parry, que percebeu elementos comuns entre a arte dos bardos sérviocroatas, ainda viva naquela época, e a linguagem formular da poesia grega (cf. PARRY, 1971). 
4. Em grego: $\tau \tilde{\omega} \mu \eta ́ v$

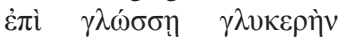

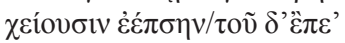

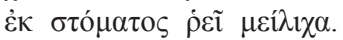
Trad.: Jaa Torrano. jeto como a phorminx, instrumento de cordas. Seus epítetos glaphyros, redonda, e ligys, clara, indicam um aspecto morfológico importante do instrumento, sua base redonda, e seu timbre, forte e claro, devido à utilização do plectro.

Esses poemas foram recitados por séculos, antes de serem colocados em escrita na era arcaica, e representam a antiga memória do povo daquela regiáo. $\mathrm{O}$ culto à deusa Mnemosyne apresentava forte analogia com a mousike. Suas filhas Musas apareciam relacionadas a campos técnicos, ou artísticos como dizemos atualmente. Em Hesíodo essas determinaçóes ainda são um pouco difusas, só posteriormente elas ganham funçôes específicas. Contudo, seus nomes nos dão algumas pistas: Thálea (da festa); Melpômene (do canto); Terpsícore (da dança); Eutérpe (da alegria); Érato (do amor); Polímnia (dos muitos hinos); Kalíope (da bela voz); Kléos (do murmurinho) e Urânia (das coisas celestes). A presença de Urânia no panteão das musas evidencia uma fronteira difusa entre os planos do que chamamos hoje ciência e arte. Urânia mais tarde será associada à astronomia. Por conta disso, não é possível aceitarmos a tradução usual do termo mousike como "arte das musas". Em primeiro lugar, a tradução mais próxima para "arte", tal como entendemos hoje, era techne, com o sentido de habilidade na produção de algo. A raiz indo-europeia tek refere-se à ideia de produzir. A tradução mais correta seria apenas "aquilo que é das musas". $\mathrm{Na}$ concepção de belas-artes desenvolvida posteriormente no Ocidente, a técnica é uma ferramenta da arte, mas na cultura grega techne era a própria arte. O termo mousike entáo parece apontar para o campo de sentido apontado por Lévi-Strauss quando se referiu a uma "ciência do concreto" (cf. LÉVI-STRAUSS, 1962, p. 11-49).

A mousike grega era a própria atividade de transmissáo de um saber, produzido pelo movimento e/ou um certo rumor sonoro, mas ao mesmo tempo gerando esse movimento e/ou rumor. Na Teogonia de Hesíodo as musas com sua sabedoria são invocadas até mesmo antes de disputas políticas, para suavizar as palavras do rei:

Elas lhe vertem sobre sua língua o doce orvalho E palavras de mel fluem de sua boca [HESÍODO, 1995, vv. 83-84, p.109] $]^{4}$. 


\section{A DISPUTA DA FILOSOFIA COM A POESIA}

Ao longo do tempo, os poetas sempre acrescentaram novos detalhes às musas, de acordo com seu desejo ou inspiração. No período clássico grego as representaçôes se intensificam e em geral elas aparecem tocando um instrumento musical. Eles são objetos técnicos que, ao serem capazes de produzir um dos componentes mais maravilhosos da natureza, o tom musical, mostram-se eficientes em dominar. Na Renascença, os instrumentos musicais se tornarão alegorias de um saber ligado à ciência e à arte.

Náo se sabe ao certo o momento preciso em que os poemas de Homero e Hesíodo foram colocados em escrita, segundo Havelock (1994, p. 163), "em algum ponto entre 700 e 550 a.C”. É provável que Hesíodo tenha cantado seus poemas nas competiçóes que se multiplicaram no século VII a.C; ele mesmo diz que ganhou uma trípoda de prêmio em uma delas no poema Os trabalhos e os dias (vv. 654-690). As competiçóes foram uma das mais fortes instituiçóes do mundo dos helenos. Eles mesmos contavam a sua história a partir da realização da primeira Olimpíada, em 776 a.C. A concepção de povo helênico estava intimamente ligada a esses jogos, que reuniam competiçóes esportivas, musicais, teatrais e de poesia, além dos famosos debates públicos e palestras sobre vários assuntos, por exemplo, "tópicos como teoria dos elementos e os constituintes fundamentais do corpo humano" (LLOYD, 1987, p. 91).

Os debates eram muito competitivos e essa qualidade fazia parte do modo de apresentação, do seu estilo. Náo havia dependência da autoridade dos deuses e nem de ninguém e os discursos versavam sobre qualquer questáo que, porventura, interessasse e preocupasse a população. O público determinava a inteligibilidade do discurso. Segundo o historiador inglês Geoffrey Lloyd, os debates possuíam algumas regras, mas elas eram bastante abertas, e o que os diferenciava dos de outras culturas antigas era justamente o fato de serem público - e ainda, ao ar livre (Cf. LLOYD, 1987, p. 90-1).

Os jogos mobilizavam toda a Hélade e uma multidão afluía às cidades que os recebiam. Por volta do século VI a.C., começam a aparecer nos debates públicos grandes oradores e filósofos. Eles entravam frequentemente em disputa com o 
mito, questionando-o. Alguns chegavam a ficar obcecados em suplantar os poetas, como nos leva a considerar o fragmento de Heráclito de Éfeso: "Homero merecia ser expulso dos certames e açoitado e Arquíloco igualmente" (1973, p. 89. [frag. 42]). Os estilos de debates também passaram a ser motivo de disputa, e rivalidades surgiram acerca de qual tipo de exposição, apresentação ou representação teria maior excelência ou valor. Uma oratória espontânea começa a dar lugar a uma técnica mais aguda. O discurso filosófico passa a disputar o espaço diretamente com os poetas.

Havelock chama a atenção para essa "nova arte da oratória, do canto" em que "o fluxo do metro épico é interrompido"; esse novo ritmo está fundado no recurso de criar polaridades e antagonismos. Havelock comenta a respeito do estilo dessa nova arte:

Esta é uma espécie diferente de ritmo, mas é ritmo. A memória é estimulada a construir uma cadeia associativa de causa e efeito e fazer a mente saltar de uma posiçáo para a oposta. (...) Auxiliares acústicos da memorizaçáo recebem o apoio suplementar de um tipo de mnemônica que se funda no sentido e não no som, isto é, opera por meio de imagens, que são antitéticas em seus efeitos emocionais. (HAVELOCK, 1982, p. 253).

A memória se afasta da materialidade da métrica, da música, da poesia e da dança e passa a ser conduzida por ideias e conceitos, em imagens antagônicas típicas do agon grego. Tales especulou se o mundo náo principiou pela umidade de água; Anaxímenes, pela qualidade gasosa do ar; Anaximandro se lançou nos abismos infinitos do ilimitado. Era preciso perguntar sobre o princípio que subjaz a todas as coisas e, para isso, as formas de apreensáo do mundo pelos sentidos eram questionadas.

A noçáo de que haveria uma estrutura subjacente ao mundo dos sentidos está presente nas vertentes mágicas de todas as culturas, contudo, no Ocidente, surgiu a suposição de que ela podia se tornar inteligível, por meio de números, mais especificamente, razóes aritméticas. Isso se dá no contexto do pitagorismo, que defendia que havia uma ordem na natureza, passível de ser conhecida por meio das razóes e proporçóes aritméticas. Essa linha de pensamento tornou-se muito poderosa com a sua associação aos tons musicais, ou seja, a 
estrutura do universo estaria em uma relação análoga a das consonâncias (symphoniai) do sistema musical grego que, por sua vez, seriam os eixos de articulação da natureza 5 . Essa concepção está presente nos fragmentos do livro Sobre a natureza de Filolau de Agrigento, que expôs a teoria provavelmente em um debate público, a julgar por sua linguagem. Filolau faz ainda associaçóes da escala musical com a astronomia.

\section{A MEMÓRIA UNIVERSAL DO ORFISMO PITAGÓRICO E DO PLATONISMO}

Os pitagóricos foram referidos muitas vezes como seguidores ou reformadores do orfismo, trazendo essa concepçáo de universalidade do conhecimento, por meio dos números, ou mathesis. Como dito anteriormente, Mnemosyne estava presente nesses cultos. Platáo incorpora alguns aspectos do orfismo em sua filosofia, em especial na associaçáo com a memória. A filosofia platônica adota a explicação metafísica pitagórica para legitimar implicaçóes éticas da música.

Na obra República, Platão narra o mito de Er, soldado armênio que é dado como morto, mas retorna ao mundo dos vivos e tem a memória do que viu e ouviu no post mortem. Nesse relato, está a concepção de harmonia das esferas: oito sereias que entoam, cada uma delas, um tom, formando uma música universal (614b-617d). Er tem acesso ao que seria o motor do universo; as oito sereias representam os sete planetas mais o céu das estrelas fixas. Não são nove musas, mas oito sereias, mantendo o universo em movimento por meio do seu canto, tal como as Musas faziam em torno de Mnemosyne. Aqui já não temos dança, nem festa, apenas o canto das sereias, ou seja, o tom musical retirado das circunstâncias de performance. Não há movimento do melos, apenas os planetas se movem, conferindo uma espacialidade ideal à música.

Em outro diálogo platônico, Menon, Sócrates explica um conceito associado à memória: a anamnese. Antes de iniciar a explicação, Sócrates recita um poema de Píndaro sobre Perséfone, a deusa que devolve os humanos à terra nove meses após a sua morte.

Aqueles que Perséfone aceita para reparaçáo dos antigos erros Suas almas ela devolve no nono mês para o sol acima

Deles surgem reis valorosos e seres de grande força e sabedoria
5. O sistema da música grega estava baseado no modelo do tetracorde, que tinha quatro notas fixas formadas pelos intervalos de quarta, quinta e oitava, selecionadas auditivamente como sendo as consonantes, symphonicas. Ver GUSMĀO (2010). 
6. Esse prefixo *ana, em grego que dizer trazer para frente, para aqui, agora, seja de trás para frente, ou de frente para trás; o sufixo ${ }^{*}$ sis significa ação, movimento.

7. É possível conjecturar se esse trecho de Platão possa ter suscitado a afirmação de Aristóteles de que aqueles que passavam pelos mistérios deveriam não "aprender" (mathein) mas "sofrer" (pathein) (ver BURKERT, 1991, p. 80, n.13).

8. Esse texto está no conjunto conhecido em latim como Parva naturalia, Pequenos tratados sobre a natureza.
Que para sempre são chamados, por todos, sagrados heróis (PLATÃO, xxxx, 81b).

Após o preâmbulo poético ao discurso filosófico, Sócrates diz que quando alguém "relembra um pequeno trecho de conhecimento - ou aprende, como dizemos comumente - não há motivo para não encontrar o restante, se mantiver um coração firme e náo se cansar da busca; pois buscar e aprender são de fato nada mais que relembrar (anamnesis $\left.{ }^{6}\right)$ " $(81 \mathrm{~d})^{7}$. Em seguida, o filósofo dá um exemplo de anamnese para seu interlocutor, Menon, chamando um escravo para levá-lo a fazer um raciocínio geométrico que o leva a descobrir como construir um quadrado que tem duas vezes a área de um quadrado dado, apenas respondendo às perguntas de Sócrates.

Durante o processo, Sócrates volta-se para Menon e diz: "Como você vê, Menon, eu náo estou ensinando nada, apenas perguntando" (82e). Sócrates reconhece uma fonte primordial de conhecimento, que ele identifica à memória, mas que náo é um arcabouço de saberes concretos e sim uma sabedoria universal.

\section{MEMÓRIA E ANAMNESE EM ARISTÓTELES}

Aristóteles buscará distinguir memória de anamese, e também afastá-las do mito. No pequeno texto Da memória e da anamnese $e^{8}$, ele dialoga diretamente com o Menon de Platáo. De início, o filósofo mostra que a memória (mneme) é um pathos ou uma hexis, isto é, algo que sucede ou pertence aos seres humanos, em contraposiçáo à energia, à ação. Quando alguém exercita a memória, conecta na alma o que antes viu, ouviu, sentiu, mas não há percepção, pois essa só acontece no presente, e nem mesmo julgamento. Ele decide investigar então em que parte da alma ocorre a memória.

Aristóteles observa que a memória implica na capacidade de formar phantasmatos, termo grego que costuma ser traduzido por imagem. E se a memória implica em phantasmatos, ele diz, deveríamos pensar que ela é uma qualidade do nous, do espírito; mas Aristóteles nega que assim seja, pois alguns animais têm memória e náo têm consciência do lapso de tempo, em grego, to genomenos, em uma traduçáo livre, o acontecido. $\mathrm{Na}$ verdade, os animais têm memória, mas o que eles não con- 
seguem realizar, é a anamnese, que é especificamente humana e que leva em consideraçáo os intervalos de tempo.

Para o filósofo, a anamnese implica uma sucessão de eventos, um encadeamento no tempo, que tem uma ordem ( $t a k-$ sis). Para que possamos praticá-la, temos de encontrar o princípio da sucessáo de eventos, da sequência. Apesar da crítica a Sócrates, esse ponto inicial tem semelhança com o "pequeno trecho" que Sócrates diz ser necessário lembrar para realizar a anamnese. Contudo, a empreitada de Aristóteles envolve fazer a crítica ao episódio do escravo do Menon:

(...) os problemas matemáticos são os mais fáceis de relembrar pois possuem um arranjo ordenado, assuntos mal-ordenados são mais difíceis de lembrar. Essa é a diferença entre relembrar e aprender, no primeiro caso a pessoa é capaz de algum modo de fazer um movimento por si mesma, para o próximo termo após um ponto de partida. Quando ele não consegue, mas apenas por outro artifício, ele não está relembrando (ARISTÓTELES, 1996, 452a).

Isto quer dizer que quando a pessoa está aprendendo ela náo consegue organizar e eleger um ponto de partida. Quando ela é capaz de fazer o movimento por si mesma, para o próximo termo após um ponto de partida, ela está realizando uma anamnese. Para exemplificar, ele fornece uma sequência de memória associativa: leite $>$ branco $>$ ar $>$ orvalho $>$ outono. Para empreender a relembrança, podemos tomar qualquer elemento da cadeia, mas ele chama a atençáo para o fato de que ponto médio é um bom princípio. A justificativa é topológica e geométrica: "se você pensa em uma série $\mathrm{AB} \triangle \triangle \mathrm{EZH \Theta}$, se você não lembra de $\mathrm{A}$, mas lembra de $\mathrm{E}$, você pode viajar em ambas as direçóes" (452 a,17-26).

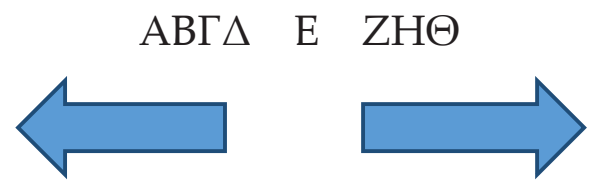

Fig. 1: Esquema gráfico a partir de texto de Aristóteles, Da memória e da anamnese (452 a,17-26)

Portanto, para que seja possível realizar a anamnese, a série associativa náo pode estar organizada aleatoriamente pois a memória percebe de maneira proporcional, em termos de 
9. A este respeito, cf. GUSMÃO, 2010. tempo. Isso fica claro com a capacidade humana de estimar lapsos de tempo, que ele diz ser similar ao que acontece com a visão: quando vemos uma coisa, conseguimos calcular se ela está longe ou perto, mesmo que não saibamos calcular em metros. Isso acontece com a memória, porque pensamos por movimentos proporcionais (analogon kinesei) (452b,11): nós náo precisamos de unidades de medida para estimar se algo aconteceu há muito ou há pouco tempo.

Ele demonstra esse tópico por meio de dois triângulos que tem o ponto comum A. São eles: ABE e ACD. Se pensamos que $\mathrm{A}: \mathrm{B}$ assim como $\mathrm{B}: \mathrm{E}$, podemos passar a $\mathrm{C}: \mathrm{D}$ pois $\mathrm{A}: \mathrm{C}$ e $\mathrm{C}: \mathrm{D}$ estão na mesma proporção que A:B e B:E (452b,15-25). Aristóteles chama esses raciocínios de movimentos. Então, ele diz, com a memória temos de reunir dois movimentos: um relacionado ao fato em si e outro à estimativa de tempo em que ele ocorreu.

Por fim, Aristóteles diz que a anamnese é somática. Ela é uma busca de um phantasmatos no corpo e a prova disso é que, quando apesar de muita concentração nós não conseguimos fazer as associaçóes, a sensação somática persiste mesmo depois de abandonarmos a busca. É o mesmo que acontece quando somos tomados por um ditado, uma melodia ou raciocínio. Mesmo parando de pensar neles, aquilo segue vindo aos nossos lábios, seguimos repetindo ou cantando aquela melodia ou repetindo o raciocínio. Para o filósofo, por conta disso, sáo os melancólicos os mais afetados pelo phantasmatos, pela imagem.

\section{CORRESPONDÊNCIAS ENTRE A ANAMNESE ARISTOTÉLICA E O MELOS ARISTOXENIANO}

Aristoxeno de Tarento foi um discípulo de Aristóteles e, como mostramos em outro estudo, sua teoria musical é de inspiração peripatética ${ }^{9}$. Aristoxeno não fala de anamnese, mas a descrição do melos em seu sistema musical, que está fundado na aisthesis e da dianoia, nos parece análoga à descrição aristotélica da anamnese.

Como dissemos, para Aristóteles, não é possível pensar sem imagens e sem a estimativa do tempo. Mas o termo imagem, tradução de phantasmatos, para nós é usualmente associado à visão. Contudo, o filósofo diz que a memória acontece a al- 
guém que lembra o que viu, ouviu e sentiu, entáo, nos parece que o termo phantasmatos tem um âmbito mais amplo que o visual, pois essa imagem pode ser sonora, musical, olfativa, ou seja, qualquer coisa que tenha sido impressa pelos nossos sentidos. O que está claro é que essa imagem é gerada a partir da aisthesis, da sensaçáo. Por isso, Aristoxeno quando fala da recepção do melos, usa a expressão "a imagem da sensação"

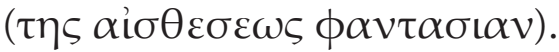

Vimos também que, para Aristóteles, a anamnese ocorre mais facilmente com as coisas ordenadas e que essa ordem não pode ser aleatória. $\mathrm{O}$ melos aristoxeniano também é uma sucessão ordenada e não acontece de maneira aleatória. $\mathrm{O}$ músico discorre sobre a ordem (taksis) do melos: "nenhuma das coisas sensíveis tem tamanha ordem" (ARISTOXENO, 1954, p.11).

Contudo, essa organização do melos, na harmônica aristoxeniana, não é um tópico discutido em termos de tempo. A dimensão do chronos é reservada aos Elementos de ritmo, outro livro de Aristoxeno, onde ele cria a noção de protos chronos, tempo inicial. Nessa obra, o tarentino náo está pensando no melos, mas na mousike, no sentido específico que esse termo tinha no período clássico: a uniáo de dança, ritmo e canto e que, para Aristoxeno, deviam ser unificadas pelo protos chronos. Nesse momento, ele se afasta de Aristóteles, para quem a sílaba deveria ser a unidade de ritmo; para Aristoxeno deveria haver uma unidade de tempo.

O melos, ou a voz, tem dois tipos de movimento: de acordo com o lugar e de acordo com o tempo: kata ton topov e kata

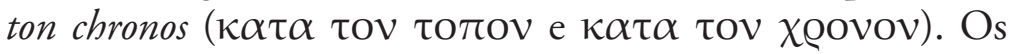
dois sistemas coexistem quase até o silêncio ( $\mu \varepsilon \chi \varrho\llcorner\sigma \iota \omega \pi \eta \zeta)$. Em Elementos de harmônica, seu foco é o movimento da voz kata ton topos. Tópos aqui significa tessitura quando se refere à distância máxima entre dois tons, produzidos pela voz ou por instrumentos. Mas também tem o sentido de lugar quando Aristoxeno está se referindo ao limite de deslocamento dos sons móveis dentro do tetracorde. Ele está pensando em uma arquitetura do melos, que é o encadeamento dos tetracordes em grandes sistemas.

Aristoxeno amplia a noçáo de movimento da teoria aristotélica, para um movimento característico da Harmônica. Ele chama a atençáo para o fato de que o que os outros, como 
Aristóteles, chamam de movimento o que para ele é repouso e movimento.

Para examinar a questão do topos da voz, ele cria uma concepção geométrica. De início, há apenas diastasis ( $\delta\llcorner\alpha \sigma \tau \alpha \sigma \iota \varsigma)$, movimentos entre o grave e o agudo, que podem se estender ao infinito, os limites sáo dados pela voz e pelo ouvido (ARISTOXENO, 1954, p. 22). Na sua arquitetura musical,

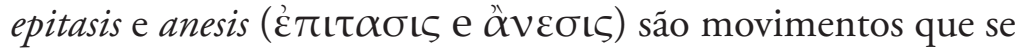
encaminham para o grave ou o agudo, mas são só movimentos

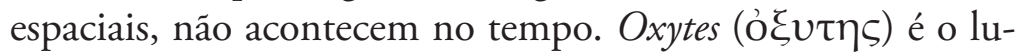
gar de chegada do agudo, e há o lugar mais agudo: oxyteros

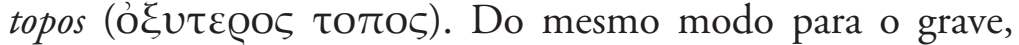
barytes ( $\beta \alpha \varrho \cup \tau \eta \varsigma)$ e o lugar mais grave de todos, baryteros

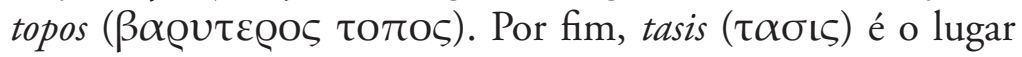
de repouso ou de imobilidade. Resumindo, epitasis e anesis são direçóes no espaço; oxytes e barytes são dimensóes e tasis, o ponto de parada, a nota ou o tom.

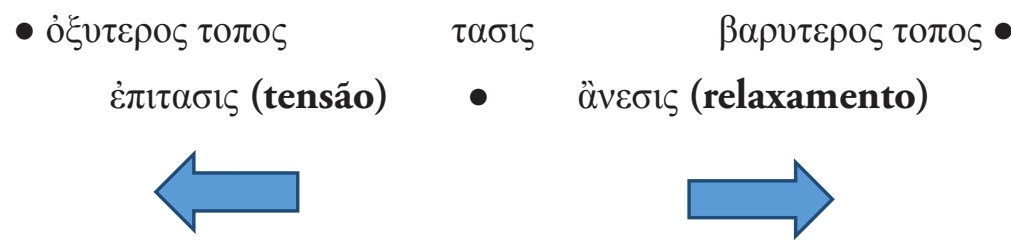

Fig. 2: Esquema gráfico a partir de texto de Aristoxeno, L'armonica (1954, p. 6-8).

Quando essa tasis se encontra no meio do sistema musical, ela é uma mese. Poderíamos dizer aproximada e anacronicamente que a mese fazia um papel próximo da tônica do sistema tonal moderno; a mese pode estar presente em ato ou em potência, ela é uma lembrança que percorre todo o melos. Essa posiçáo central, ocupada pela mese tem similaridade com o termo mediano do triângulo aristotélico. É possível pegar uma tasis, um tom, uma nota, em qualquer ponto, e, se houver proporcionalidade entre as duas, ou seja, se ela for uma consonância, alcançar outro. Se for a mese, o ponto central, é ainda mais simples. Aristoxeno tem uma concepção topológica dos sons, que sáo organizados em sistemas nos quais a voz tem movimento e percorre um lugar. $\mathrm{O}$ melos é construído por uma ação análoga à anamnese, articulando partes, reven- 
do imagens sonoras, estimando ritmicamente as distâncias, sem precisar de sistema métrico para tal.

Aristoxeno falará de memória em um único momento em Elementos de harmônica e a descrição nos parece análoga a da anamnese peripatética, quando Aristóteles afirma que para realizá-la temos de reunir o fato em si e a estimativa de tempo em que ele ocorreu. Aqui os dois momentos são a escuta e o pensamento (aisthesis e dianoia):

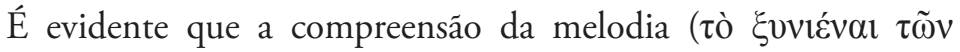
$\mu \varepsilon \lambda \omega \delta o v \mu \varepsilon \dot{\varepsilon} v \omega v)$ consiste em seguir com a escuta e o pensamento (aisthesis e dianoia) todo a sucessão das notas. De duas coisas vem a compreensão do vir a ser do melos e das outras partes da mousike.: a percepção e a memória. Ter percepção do que está acontecendo e lembrar o que aconteceu. De nenhum outro modo está o desenrolar da música (ARISTOXENO, 1954, p. 59).

\section{PALAVRAS FINAIS}

Como vimos, a anamnese para Aristóteles é uma ação especificamente humana, algo que podemos dizer também da música. Ele afirma que algumas pessoas têm boa memória, enquanto outras têm boa capacidade de anamnese, mas, enquanto muitos animais conhecidos têm memória, nenhum tem anamnese. É possível fazer uma relação entre as conclusôes aristotélicas e as de neuropsicólogos que, nas últimas décadas, vêm estudando a habilidade chamada de ouvido absoluto. Todos sabemos que essa habilidade envolve uma boa memória para tons musicais além de uma forma linguística apropriada para rotular a nota ou a peça musical. Nesse caso, a discussão envolve um aspecto cultural pois indivíduos que tenham culturas musicais distintas, com tipos diferentes de escalas e afinaçóes, estáo por vezes em campos quase irredutíveis entre si. Contudo, nada indica que uma pessoa que tenha ouvido absoluto, ou seja, que possua esse tipo de habilidade mnemônica, venha a ser melhor músico que aquele que não o possua. Ambos teráo facilidades e dificuldades, isso sem dizer que a linha que os separa não é clara. Os estudiosos observaram, contudo, um dado interessante: alguns animais como pássaros, macacos e lobos demonstraram possuir ouvido absoluto sem, no entanto, ter desenvolvido a capacidade de fazer 
música. Aristoxeno, o músico, talvez completasse: sem a capacidade de harmonizar ou articular o melos.

Concluímos que os estudos de epistemologia antiga nos conduzem a fontes bem mais variadas que as que aprendemos a considerar. Homero, Hesíodo ou Ésquilo nos apresentam modulaçóes do conhecimento que abrangem planos epistêmicos bem interessantes e muito vastos. Sem mencionarmos as descriçôes e mapeamentos feitos por Platão e Aristóteles sobre várias formas de cognição, como vimos em relação à memória. Se Ovídio, nas suas Metamorfoses, chamou as Musas de Mnemônides (v. 268), só nos resta indagar que outras relaçóes entre música e memória estamos ainda por reconhecer.

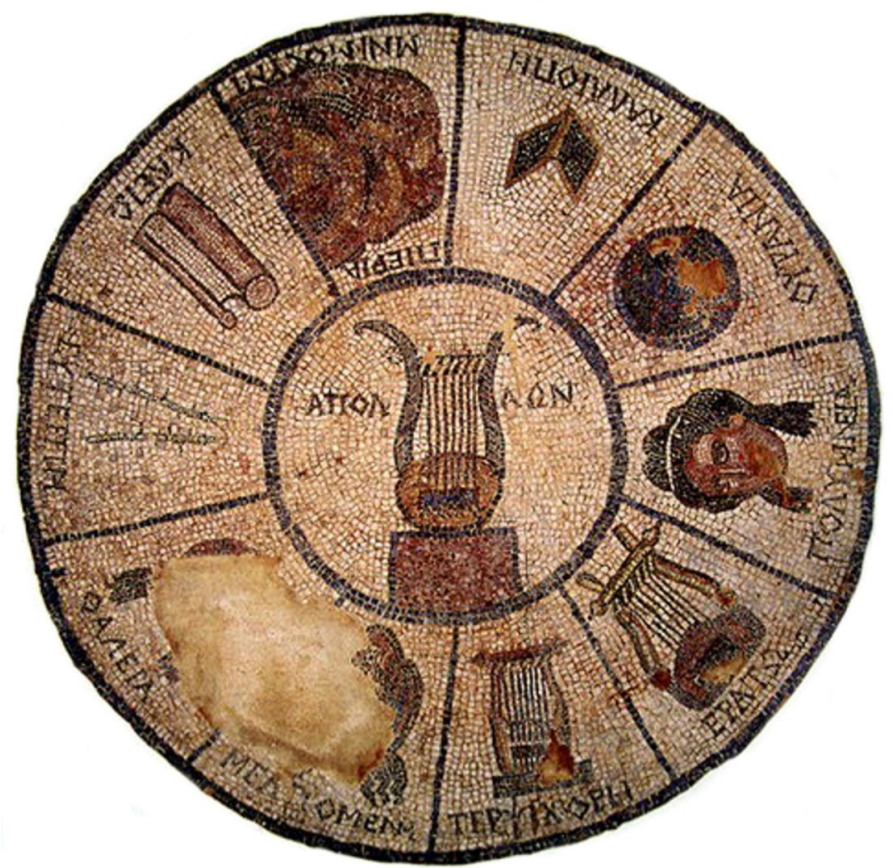

Fig. 3: Mosaico de chão do séc. I a.C com representações de Apolo, Menemosyne e as Musas: Kaliope, uma tábua de escrita; Urania, um globo celeste; Polymnia, uma face seria; Erato e Terpysicore, cítaras; Melpomene e Thalea, máscaras trágica e cômica; Euterpe, aulos duplo; Kleos, pergaminho e Mnemosyne, o monte da Piéria. No centro, Apolo é representado como uma cítara. Museu Arqueológico de Elis, Grécia [TBA] 


\section{REFERÊNCIAS BIBLIOGRÁFICAS}

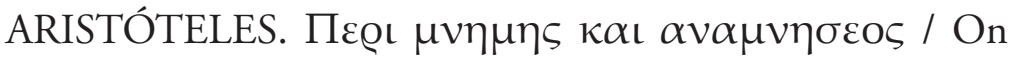
memory and recollection. In: Parva naturalia. Cambridge: Harvard University Press, 1996. (Loeb Classical Library).

ARISTOXENO. Elementa harmonica. In: RIos, R. DA (Ed.) L'armonica. Roma: Typis Publicae Officinae Polygraphicae, 1954.

The Harmonics. In: Macran, H. (Ed.) The harmonics of Aristoxenus. Hildesheim/New York: Georg Olms, 1974.

BURKERT, W. Antigos cultos de mistério. São Paulo, EDUSP, 1991.

FILOLAU. Sobre a natureza. In: Pré-socráticos. São Paulo: Abril Cultural, 1973, p. 255-58. (Coleção Os Pensadores).

GUSMÃO, Cynthia. A harmônica na Antiguidade grega. Dissertação (Mestrado em Filosofia). Faculdade de Filosofia, Letras e Ciências Humanas (FFLCH), Universidade de São Paulo (USP), São Paulo, 2010.

HAVELOCK, Eric. A revolução da escrita na Grécia. São Paulo: Unesp/Paz e Terra, 1994.

HERÁCLITO. Fragmentos. São Paulo: Abril Cultural, 1973, p. 79-97. (Coleçáo Os Pensadores).

HESÍODO. Os trabalhos e os dias. In: AmzalaK, M.B. Hesiodo e o seu poema "Os trabalhos e os dias". Lisboa: Academia das Ciências de Lisboa, 1947.

. Teogonia. In: Torrano, J. Teogonia de Hesíodo.

Origem dos deuses. São Paulo: Iluminuras, 1995.

HOMERO. Ilíada. Tradução: Carlos Alberto Nunes. São Paulo: Ediouro, s.d.

di, 1989.

. Odissea. Tradução: R.C. Onesti. Torino: Einau-

Odisseia. Tradução: Jaime Bruna. São Paulo:

Cultrix, 1997.

CASSOLA, Ferrandina. Inni omerici. Rocca San Casciano: Mondadori, 1997.

LÉVI-STRAUSS, Claude. La pensée sauvage. Paris: Plon, 1962. LLOYD, G.E.R. The revolutions of wisdom - studies in the claims and practice of ancient Greek science. Berkeley: University of California Press, 1987. 
MAAS, Martha E Jane McIntosh Snyder. Stringed instruments in ancient Greece. New Haven/London: Yale University Press, 1989.

PARRY, Milman. The traditional epithet in Homer. In: The making of homeric verse. The collected papers of Milman Parry. New York: Oxford University Press, 1971. p. 1-23.

PLATÃO. La Repubblica. LozzA, G. (Ed.) Milano: Mondadori, 2006.

. Meno. London: Penguin Classics, 1956.

Timaeus. In: BurY, R.G. Plato in twelve volumes. Cambridge/London: Harvard University Press, 1989. (Loeb Classical Library, v. 9).

SORABJI, Richard. Aristotle on memory. Chicago: The University of Chicago Press, 2004.

OVÍDIO. Metamorfoses. Lisboa: Editora Cotovia, 2007. 